\title{
Solid State Reaction Detected Between Hexagonal Boron Nitride and Iron During Sintering
}

\author{
Kaline Pagnan Furlan ${ }^{1}$, Deise Rebelo Consoni ${ }^{1,2}$, Breno Leite ${ }^{3}$ and Aloisio Nelmo Klein ${ }^{1}$ \\ ${ }^{1}$ Materials Laboratory (LabMat), Federal University of Santa Catarina, Florianópolis, Brazil. \\ ${ }^{2}$ LCME, Federal University of Santa Catarina, Florianópolis, Brazil. \\ ${ }^{3}$ JEOL USA Inc, Peabody, United States.
}

Nowadays the development of new materials is mainly dependent on performance requirements, which are related to the functional conditions, environmental aspects and application design. Dry selflubricating materials (containing solid lubricants) are examples of material specifically designed to operate in conditions where the presence of liquid lubricants (namely oils and greases) is not allowed or does not provide enough lubrication for better performance [1]. Solid lubricants can replace liquid lubricants when used as films or incorporated in the bulk of the component (volumetric dispersion). In the latter case, powder metallurgy is the common process path. Through powder metallurgy it is possible to include a large number of distinct solid lubricant particles, such as $\mathrm{MoS}_{2}, \mathrm{WS}_{2}, \mathrm{MoSe}_{2}$ and h-BN, to the metallic matrix. The selection of the solid lubricant phase depends on the matrix chemical makeup to avoid undesirable reactions among materials. In this work iron powder (Höganäs, AHC 100.29, $\mathrm{d} 50=100 \mu \mathrm{m})$ and $\mathrm{h}-\mathrm{BN}$ powder $(9 \%$ volume, Momentive AC6004, d50=13 $\mu \mathrm{m})$ were mixed in a Yshape mixer for 60 minutes, compacted in a semi-automatic press (700 MPa) and sintered at $1150{ }^{\circ} \mathrm{C}$ for 60 minutes inside a tubular resistive furnace under a 95\% $\mathrm{Ar} 5 \% \mathrm{H}_{2}$ atmosphere.

The metallographic analysis results (optical microscope, transversal section, etched with Nital 2\%) revealed the existence of reaction phases newly formed (Fig.1-A), which exhibited a cementite like appearance and reduced size ( 2 to $40 \mu \mathrm{m})$, mainly formed at grain boundaries, near the h-BN reservoirs. This phase has been characterized as having high microhardness values (Fig.1-B) when compared with the iron matrix, nearly 4 times higher. X-ray diffraction allowed the identification of this phase as an iron-nitride $\left(\mathrm{Fe}_{8} \mathrm{~N}-\gamma^{\prime}\right)$, however the diffractogram peaks also points out the possibility of an iron carboboride $\left(\mathrm{Fe}_{23}(\mathrm{C}, \mathrm{B})_{6}\right.$ PDF 12-0570) phase. Tao et al. [2] described the formation of the same reaction phase $\left(\mathrm{Fe}_{8} \mathrm{~N}\right)$ between iron and h-BN after powders' milling. Momeni and collaborators [3] also suggested the formation of a new phase during sintering, but they did not characterize it. Mahathanabodee et al.[4] characterized a similar phase formed in SS 316L+h-BN composites during sintering as a boride. The Energy-dispersive X-ray spectroscopy analysis (EDS) (Fig.2) confirmed the formation of a carbo-boride phase showing that $\mathrm{h}-\mathrm{BN}$ is not an inert lubricant in the iron-based matrix composites. The carbon is present in the $\mathrm{h}-\mathrm{BN}$ powder as a residual element from its production (reducing of boric acid with carbon). We have utilized a Thermo EDS detector (Noran System on a JEOL JSM-6390LV) and a routine multivariate statistical analysis (COMPASS) developed by Paul Kotula [5] along with low accelerating voltage to characterize the phases present after sintering. Results were confirmed by the processing and displaying of quantitative weight \% maps. As consequence of this reaction, the tribological properties of the material were impaired, resulting in friction coefficient above 0.2 and significant wear, thus not making the combination of iron and this type of h-BN a suitable selflubricating material. [6] 
References:

[1] C. Busch (2007), In: Lubricants and Lubrication, edited by T. Mang and W. Dresel, Wiley-Vch.

[2] J.G. Tao et al. (2004): Journal of Alloys and Compounds. 384, (1-2): 268-273.

[3] M. Momeni et al (2012) : Powder Metallurgy. 55, (3): 212-221.

[4] S. Mahathanabodee et al (2013) : Materials \& Design. 46, (0): 588-597.

[5] Paul G. Kotula et al (2002). Microscopy and Microanalysis, 8 (Suppl. 02): 648-649.

[6] Authors acknowledge CNPq (grant \# 163569/2014-2), Whirpool and BNDES for research funding. Research supported by LCME-UFSC.
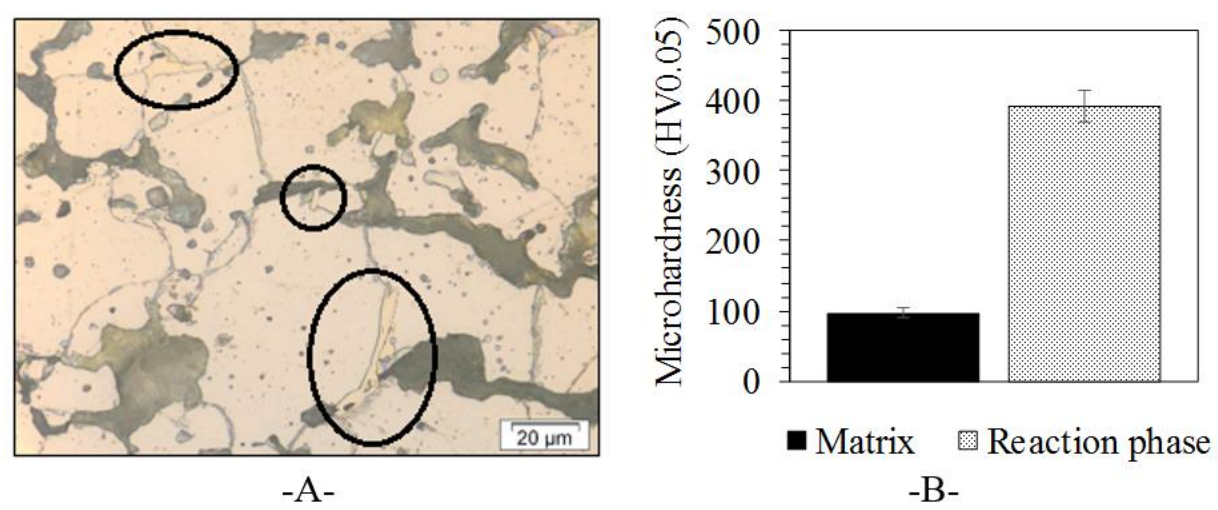

Figure 1. (A) microstructure of the sintered composite showing the matrix and reaction phase (indicated by the ellipsoidal markers), dark regions are pores and (B) Vickers microhardness comparison between the matrix and reaction phase.
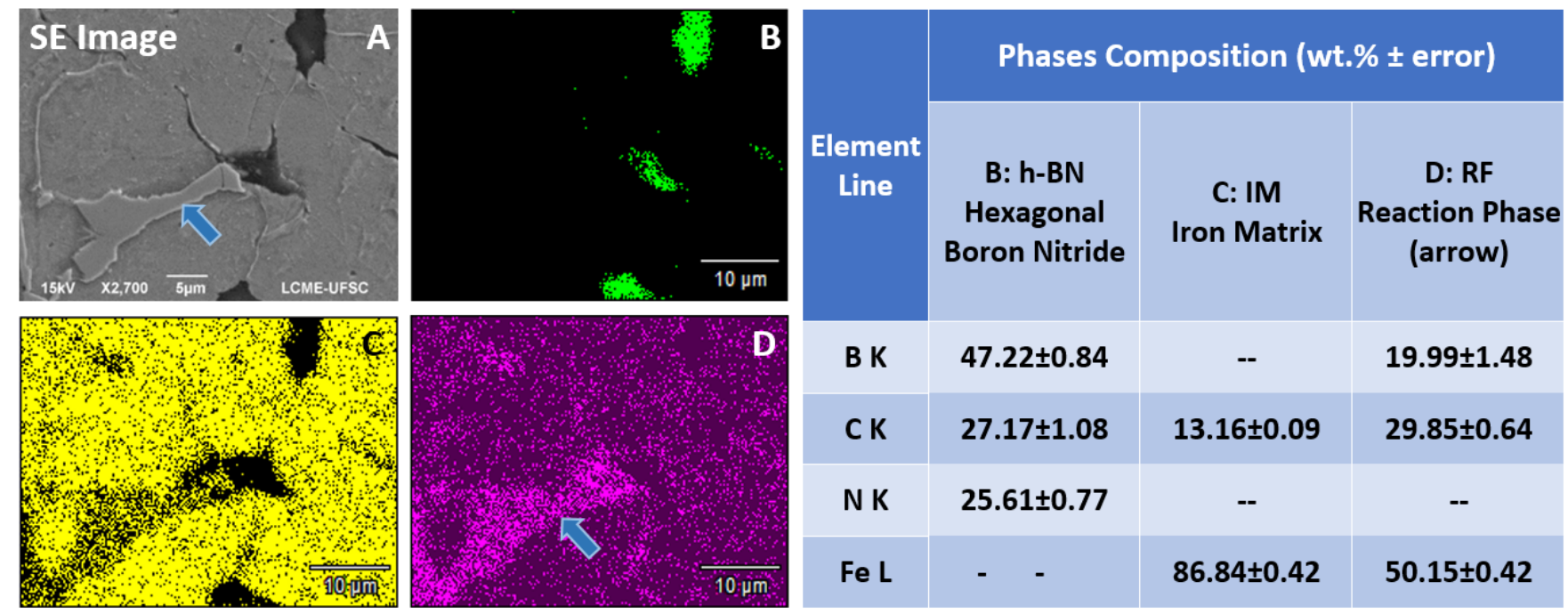

Figure 2. Phase maps of the region containing the reaction phase. Phase maps have been extracted from the original element maps by utilizing hyperspectral imaging tools available on the Noran System software. Phase maps isolated the iron matrix (C), the hexagonal boron nitride area (B) and the reaction phase (D). 